University of Nebraska - Lincoln

DigitalCommons@University of Nebraska - Lincoln

$11-2011$

\title{
(Re)Conceptualizing Intercultural Communication in a Networked Society
}

\author{
Damien S. Pfister \\ University of Nebraska-Lincoln, dpfister2@unl.edu \\ Jordan Soliz \\ University of Nebraska-Lincoln, jsoliz2@unl.edu
}

Follow this and additional works at: https://digitalcommons.unl.edu/commstudiespapers

Part of the Communication Technology and New Media Commons, and the International and Intercultural Communication Commons

Pfister, Damien S. and Soliz, Jordan, "(Re)Conceptualizing Intercultural Communication in a Networked Society" (2011). Papers in Communication Studies. 24.

https://digitalcommons.unl.edu/commstudiespapers/24

This Article is brought to you for free and open access by the Communication Studies, Department of at DigitalCommons@University of Nebraska - Lincoln. It has been accepted for inclusion in Papers in Communication Studies by an authorized administrator of DigitalCommons@University of Nebraska - Lincoln. 


\title{
(Re)conceptualizing Intercultural Communication in a Networked Society
}

\author{
Damien Smith Pfister, Assistant Professor, Department of Communication Studies, \\ University of Nebraska-Lincoln
}

Jordan Soliz, Associate Professor, Department of Communication Studies, University of Nebraska-Lincoln

Corresponding author: Damien Smith Pfister, Department of Communication Studies, University of Nebraska-Lincoln, 439 Oldfather Hall, Lincoln, NE 68588, USA; email dpfister2@unl.edu

\begin{abstract}
We offer four theses about how intercultural communication is altered in a digitally networked era. Digital media shape intercultural communication by (I) producing new public fora capable of (2) hosting rich, multimodal "spaces" of contact on (3) a scale of many-to-many communication that (4) challenges traditional modes of representation.
\end{abstract}

Keywords: digital media, intercultural communication, 2009 Iran protests, networked communication

s internetworked media technologies gradually diffused throughout the world, they
have often been sparks for intercultural dialogue. Internet websites enabled web-
savvy organizations, like the Zapatista Army of National Liberation, to circulate their
views throughout the 1990s. The power of citizens to communicate directly with each
other through digital media was not fully apparent until late 2002, when the pseudon-
ymous Salam Pax began reporting through his blog what life was like for Iraqis in the
run-up to the 2003 combat operations. Since then, citizens have relied on the tools of dig-
ital media to coordinate protests internally and communicate with outside audiences in
a number of colorful revolutions: Rose (Georgia, 2003), Orange (Ukraine, 2004-2005),
Saffron (Burma, 2007), Green (Iran, 2009), and Jasmine (Tunisia, 2011). In January 2011,
Egyptian citizens, mobilizing primarily through Facebook, organized protests that drew
concentrated global attention and ultimately replaced the authoritarian Hosni Mubarak
with a potentially more democratic electoral process. Global turmoil prompts citizens
to learn more about each other, and digital media fuel intercultural communication on
a scale and of a kind that is a significant departure from the mass-mediated contacts of 
the last several centuries. In contrast to Gil Scott-Heron's famous line that "the revolution will not be televised," these revolutions were not only televised but blogged, photographed, videoed, and, later, twittered. Although, as Morozov (2010) has cautioned, it is easy to overstate the influence of digital networks in such protests, we believe that one perhaps overlooked effect of these protests was to fuel intercultural communication on a world-historic scale.

The 2009 Green Revolution in Iran is an appropriate focal point to explore the relationship between digital media and intercultural communication because the widespread use of the microblogging service Twitter by protestors earned it the nickname of the "Twitter Revolution." Information on the protests, spurred by electoral irregularities that galvanized the reform candidate Mir Hossein Mousavi's supporters to rally against incumbent Mahmoud Ahmadinejad, was readily available on an array of digital communication networks. Using examples from the aftermath of the 2009 election in Iran and merging work from intercultural, rhetorical, and intergroup traditions, we offer four theses capable of stimulating new research and theorizing on the connections between digital media and intercultural communication.

\section{Digital Media Enable, and Potentially Constrain, Intercultural Communication Through Publicity}

Analogies drawn between the printing press and the internet are apt in highlighting how increased publication of viewpoints widens the possibilities for social identification. The internet, by reducing cost and access barriers, albeit unevenly, produces a range of fora from websites to blogs to social networking sites and microblogs that host intercultural dialogues. These new sites, Froomkin (2004) argues, help constitute communities of discourse united by shared interest and, in some cases, even produce novel styles of communication like status updates and remixes. These fora can serve as thriving sites of intercultural communicative exchange when they are unmediated - or, at least, minimally mediated - by third parties. That internetworked communication obviates intermediaries like newspaper editors is a potential boon to intercultural communication: No longer do gatekeepers patrol the boundaries of what shall and shall not be made public by people from other cultures. The diffusion of digital media into everyday life invites us to consider the free speech issues that should accompany intercultural dialogue; namely, that participants must be able to publicly thematize all facets of culture without concern for their personal safety.

It seems unlikely that the Iranian protestors would have been as successful in mobilizing global public opinion against the 2009 election results without their reliance on networked digital media. Iranians have taken to new web tools - the Persian blogosphere, for example, is a vibrant, large communication network - and were thus primed to make public the unfolding tension after the election results. Pictures of Iranians holding their camera phones in crowds flooded the U.S. press coverage of the protestors. These images served as representative anecdotes of the publicity potential of networked media, and, doubtless, functioned to put the Iranian state on notice that it, too, was being watched. Primarily through Twitter, protestors were able to upload updates about protests, pic- 
tures of rallies, and news about Revolutionary Guard crackdowns. These digital tendrils often initiated dialogue between Iranian citizens and people from all over the globe: Twitter made direct communication much easier.

The crackdown by the Iranian government, and the attendant chilling effects achieved through surveillance and outright censorship, identify how digital media may ultimately constrain intercultural communication. Though digital media are generally hailed as enhancing freedom and liberty, in some ways they make the control of populations through surveillance easier. Without privacy and anonymity safeguards, which media users often underutilize, every communicative node can be traced in networked environments and, unfortunately, this is precisely what the Iranian state did. By tracing Internet Protocol (IP) addresses and phone records, defenders of the status quo in Iran were able to identify, arrest, and likely execute many of the key organizers and digerati of the protests. Digitally networked environments can spur intercultural engagement only to the extent that surveillance does not limit topics and styles of communication.

\section{Through Multimodal Forms of Communication, Digital Media Offer New and Unique "Spaces" for Intercultural Communication}

Since Allport's (1954) seminal work, The Nature of Prejudice, scholars from multiple disciplines have focused their inquiries on identifying and understanding the facilitating conditions necessary for potential positive outcomes of contact (e.g., reducing prejudice) between different social groups (for review, see Brown \& Hewstone, 2005). Historically, the corpus of this work has focused on face-to-face (FtF) interactions. Yet, in recent years, researchers have begun to turn their attention to the promise of electronically mediated contact. For instance, Schiappa, Gregg, and Hewes (2005) demonstrate that interactions through television or movies with actual or fictional characters can offer the same positive outcomes as FtF interactions. The technological advancements in digitally networked media and the exponential growth in the public's understanding and use of these media are leading to more opportunities for interaction. Thus, digital media offer unique contexts - or what Harwood (2010) refers to as "contact spaces" that often move beyond FtF and textual modes of communication. Attending to the dynamics and richness of digital media can help to theorize its role in intercultural communication.

The richness of multimodal media is evident in the widely circulated video of the dying Iranian protestor, Neda Agha-Soltan. Viewers of this video, recorded with a phone camera by a bystander, witnessed the tragedy of a dying human and the panic of those trying to save her as she struggled for life after being shot-by all accounts, unintentionally - by police forces. Within hours, this video was uploaded to YouTube where it would ultimately be viewed by millions of people. Observers at the time noted that never before has a death been witnessed by so many; consequently, Neda became the iconic figure of the protests for those within and outside of Iran. For those outside of Iran, the sights and sounds of the video accomplished what no textual description or third-person account could accomplish. The video served as a "space" for intercultural contact in which 
the otherness of the Iranian people and any intercultural or global differences were transcended by the life and death struggle of a fellow human. In other words, this is an example where digital media allow a distal (inter)cultural experience to become more cognitively and emotionally proximal. Whether the changes in cultural perceptions were long standing or fleeting, the video of Neda enabled viewers to attain what Allport (1954) called the "hopeful possibility" of humanity as an in-group.

Although not as dramatic as images of Neda's death, videos of protests, police crackdowns, and night-time raids were often captured illegally and uploaded during the protests. These videos provided almost immediate, highly rich aural and visual representations of the election's aftermath. Viewers were not limited to textual representations of Iranians but exposed to a wider array of sensory experiences created by language, architecture, murals, and public and private spaces. Visual representations offered an enhanced experience compared to more traditional, textualized narrative accounts of cultural phenomena. Building on the idea of a "linguistic landscape" (see Shohamy \& Gorter, 2009), the ocularcentric culture of digital media can be seen as creating an "imagistic landscape" in which the richness of media provides a "feel" of a place or situation through the visual representation of other groups. In our networked society, mediated intercultural contact should not be viewed as a vitiated form of FtF interactions. Rather, digital media offer new "spaces" and (re)conceptualizations of intercultural encounters.

\section{Digital Media Facilitate Intercultural Communication on a New Scale: Many-to-Many}

Intercultural scholarship - like communication scholarship more generally - tends toward communication models that privilege dialogue in dyads or small groups. The prevalence of the term "intercultural dialogue" in readers and textbooks over "intercultural dissemination," to use a common opposition, suggests how past research has focused on few-to-few intercultural communication (see Peters, 1999). Such a focus has undoubtedly been warranted given the kinds of media historically available to facilitate intercultural contact. However, networked communication technology supports many-to-many communication that blends dialogue and dissemination on a broad scale. One implication for intercultural communication that stems from the growth of many-to-many communication fora is the increase in multiperspectivalism (Bruns, 2006; Gans, 2011; Pfister, 2011). In contrast to the traditional broadcast press, which generally adheres to a pro/con or he said/she said binary format, many-to-many communication supports the expression of a wide variety of opinions without artificial narrowing. In the context of Iran, blogs, social networking sites, and Twitter supported robust dialogue internally about movement strategy, and spurred conversation with external audiences concerning recent events and the ways that global publics could show solidarity. The Twitter user "persiankiwi," for example, played a central role in circulating the latest protest updates but was also a locus for global networked publics to share advice on how to acquire the best information on Iranian life, on optimal movement-building strategies, and on ways to mobilize 
international support. Although some version of the traditional transmission modeland, of course, its more sophisticated variants - might be adapted to account for the phenomenon of "retweeting" in many-to-many communication contexts, intercultural scholars might take the opportunity to theorize how the change in scale might challenge even these basic theories of communication.

\section{Digital Media Offer New Modes of Representation that Shape Intercultural Communication and Perceptions}

Research on mass media representations of difference has consistently revealed the influence of the political economy of the media: Representations of the "other" tend toward the stereotypical, the reductive, and the sensationalist (see the collection by Dines \& Humez, 2002). Since the costs of broadcast media are so high, the drive for advertisement revenue to support programming often results in unflattering representations of out-groups. Much communication scholarship aims to understand and critique the influence of mass media messages. But what happens when publication becomes so cheap that almost anyone can do it? How does that change the representational matrix? The internet has "democratized" representation by allowing individuals to represent themselves and their various groups rather than simply being represented. The range of representations circulated through digital media certainly seems broader than mass media, though further empirical research will be needed to confirm that claim. It would be naïve to assume that the problems of representation that inhere in the mass media have been totally overcome with digital media; there is obviously an emergent political economy of digital media that is contiguous to prior formations.

However, as the case of the Iranian protestors shows, the ability to represent oneself changes the terms of intercultural communication. In contrast to the television coverage of the Iran hostage crisis in 1979, which Larson (1986) found emphasized elite interpretations of events, Iranian citizens were able to provide their own account of the unfolding post-electoral situation. They were able to represent their own culture, demands, and images of events. Prior to the election protests, Iran was primarily known as a "member" of the infamous "Axis of Evil," and U.S. perceptions of Iran were based on views of the government and/or iconic figures (e.g., Ahmadinejad). As the global community was exposed to messages, videos, and discussions with protestors and the Iranian public, the people of Iran were disaggregated from the government of Iran. Evident in these events was that digital media literally and figuratively offered the opportunity for a plurality of voices (Mitra \& Watts, 2002). In turn, a more colorful palette of media representations can ameliorate stereotypes and homogenous perceptions of cultural groups - all barriers to overcome for effective intercultural communication.

Iran, in the summer of 2009, marked a turning point in the normalization of global intercultural communication through digital media. Iran was not the first country to witness the convergence of a new media technology with democratic protest movements nor, as the more recent and vivid demonstrations in Tunisia and Egypt illustrate, will it be the last. To understand how digital media have shaped intercultural communication, 
we invite scholars to explore the themes we have articulated in this essay. Specifically, researchers might investigate questions such as the following: How does publicity enable and/or constrain intercultural communication; how does the multimodal nature of digital media offer new spaces for contact; how does many-to-many communication refigure interaction between cultures; and how does cultural representation shift with digital media? These questions can serve as loci for a research agenda that unites the study of intercultural communication with networked communication technologies.

\section{References}

Allport, G. W. (1954). The Nature of Prejudice. Reading, MA: Addison-Wesley.

Brown, R., \& Hewstone, M. (2005). An integrative theory of intergroup contact. Advances in Experimental Social Psychology, 37, 255-343.

Bruns, A. (2006). Wikinews: The next generation of alternative online news? SCAN Journal, 3(3). Retrieved from http://scan.net.au/scan/journal/print.php?j_id=9\&journal_id=69

Dines, G., \& Humez, J. M. (2002). Gender, Race, and Class in Media: A Text-Reader. Thousand Oaks, CA: Sage.

Froomkin, A. M. (2004). Technologies for democracy. In P. Shane (ed.), Democracy Online: The Prospects for Political Renewal through the Internet (pp. 3-20). New York, NY: Routledge.

Gans, H. (2011). Multiperspectival news revisited: Journalism and representative democracy. Journalism, 12(1), 3-13.

Harwood, J. (2010). The contact space: A novel framework for intergroup contact research. Journal of Language and Social Psychology, 29, 147-177.

Larson, J. F. (1986). Television and U.S. foreign policy: The case of the Iran hostage crisis. Journal of Communication, 36(4), 108-130.

Mitra, A., \& Watts, E. K. (2002). Theorizing cyberspace: The idea of voice applied to the internet discourse. New Media and Society, 4, 479-498.

Morozov, E. (2010). The Net Delusion: The Dark Side of Internet Freedom. New York, NY: Public Affairs.

Peters, J. D. (1999). Speaking into the Air: A History of the Idea of Communication. Chicago, IL: University of Chicago Press.

Pfister, D. (2011). Networked expertise in an era of many-to-many communication: On Wikipedia and invention. Social Epistemology, 25(3), 217-231.

Schiappa, E., Gregg, P. B., \& Hewes, D. E. (2005). The parasocial contact hypothesis. Communication Monographs, 72, 95-118.

Shohamy, E., \& Gorter, D. (2009). Linguistic Landscape: Expanding the Scenery. New York, NY: Routledge. 